\title{
Decoupling Analysis on Pressure Fluctuation and Needle Valve Response for High Pressure Common Rail Injector
}

\author{
Wang Hao , Zhao Dongchang, Lv Wang \\ Automotive Data Center, China Automotive Technology and Research Centre, Tianjin 300300, China
}

\begin{abstract}
In the process of multiple injections, the influence of different injections makes the controlling of cycle fuel injection quantity more difficult. The high pressure common rail (HPCR) simulation model is established in AMESim environment. Through the method of combining numerical simulation and experiment test, it is found that the strong coupling of pressure fluctuation and needle valve response is the fundamental reason, which leads to the fluctuation of main injection fuel quantity (MIFQ) with dwell time (DT). The result shows that the largest fluctuation quantity is $3.6 \mathrm{~mm} 3$ when the reference value of main injection is $60.0 \mathrm{~mm} 3$. Non-damping LC hydraulic system model is also established. Through the analysis of the model, reducing the length-diameter ratio of internal oil duct and the delivery chamber volume are decoupling methods to the strong coupling.
\end{abstract}

\section{Introduction}

High pressure common rail is a complex system that coupling with electronic, magnetic, machine and liquid. Different parts will interact when the fuel injector is working [1-2]. Needle valve response is depending on delivery chamber pressure (DCP). The opening of needle valve can lead to pressure fluctuation in the delivery chamber, and the pressure fluctuation can impact the operating of needle valve as well. Especially in the process of multiple injections, dwell time is short between different injections, and the operating frequency is fast, which leads to the effect of coupling of pressure fluctuation and needle valve response can be particularly evident so that the actual fuel injection value cannot correspond with the theoretical injection value. As mentioned above, it can deteriorate the working condition of diesel engine, and the economic and emission performance can be influenced as well [3-4].

Simulation model of high pressure common rail was established in AMESim environment based to study the interactions between different injections in the process of multiple injections. In addition, the impact of the pilot injection to MIFQ and the fundamental reason of MIFQ fluctuating with DT are also studied and revealed. It also obtains the decoupling methods to the coupling of pressure fluctuation and needle valve response. Consequently, it provides a theoretical basis to the stability controlling of fuel quantity in the process of multiple injections.

\section{Simulation model of HPCR system}

As shown in Fig. 1, the simulation model of the HPCR system with electronic control is established in AMESim environment. It mainly consists of feed pump, common rail and electronic control injector. Main parameters of the model are shown in Table 1.

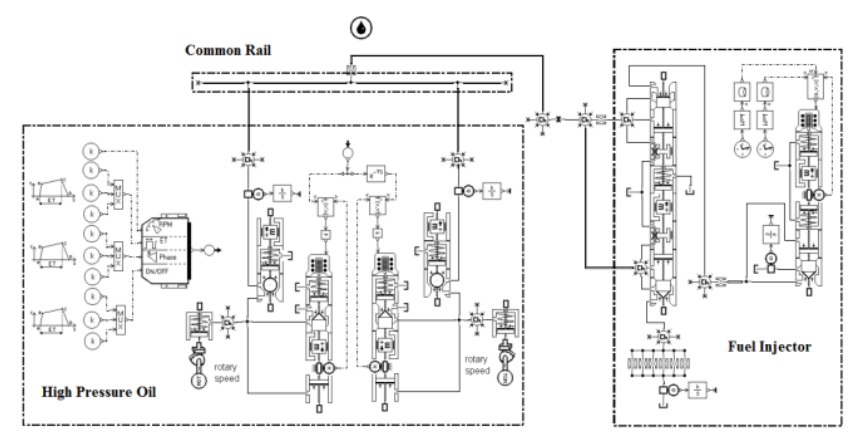

Figure 1. AMESim simulation model of HPCR system

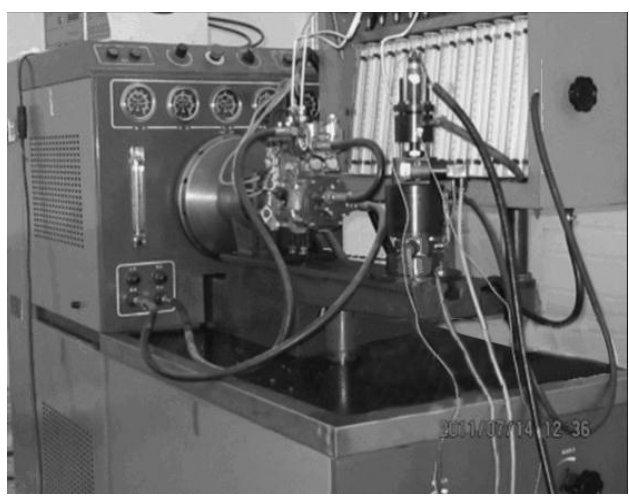

Figure 2. HPCR system test bench 
Table 1. The main parameters of the simulation model

\begin{tabular}{|c|c||c|c|}
\hline Parameter & Value & Parameter & Value \\
\hline $\begin{array}{c}\text { Pump cam } \\
\text { maximum lift } / \mathrm{mm}\end{array}$ & 9 & $\begin{array}{c}\text { Control chamber } \\
\text { outlet } / \mathrm{mm}\end{array}$ & 0.24 \\
\hline $\begin{array}{c}\text { Common rail pipe } \\
\text { inner diameter/mm }\end{array}$ & 10 & $\begin{array}{c}\text { Needle valve } \\
\text { maximum lift/mm }\end{array}$ & 0.35 \\
\hline $\begin{array}{c}\text { Common rail pipe } \\
\text { length /m }\end{array}$ & 0.3 & $\begin{array}{c}\text { Needle valve spring } \\
\text { pre-tightening force } \\
/ \mathrm{N}\end{array}$ & 30 \\
\hline $\begin{array}{c}\text { Control valve } \\
\text { maximum lift/mm }\end{array}$ & 0.08 & $\begin{array}{c}\text { Spray hole } \\
\text { diameter/mm }\end{array}$ & 0.15 \\
\hline $\begin{array}{c}\text { Control chamber } \\
\text { inlet } / \mathrm{mm}\end{array}$ & 0.27 & $\begin{array}{c}\text { Spray hole flow } \\
\text { coefficient }\end{array}$ & 0.8 \\
\hline
\end{tabular}

HPCR system test bench is showed in Fig.2. To ensure the accuracy of the simulation model, 1000r/min cam speed and $120 \mathrm{Mpa}$ common rail pressure shall be adopted to compare the result of simulation and experimental measurement. As shown in Fig.3, common rail pressure fluctuation keeps stable after several cycles. As shown in Fig.4, the fuel injection rate curve of simulation result highly corresponds with the experimental measurement. Thus, the simulation model can simulate the diesel HPCR system accurately, and it can cater the requirements of calculation and analysis of fuel injection system.

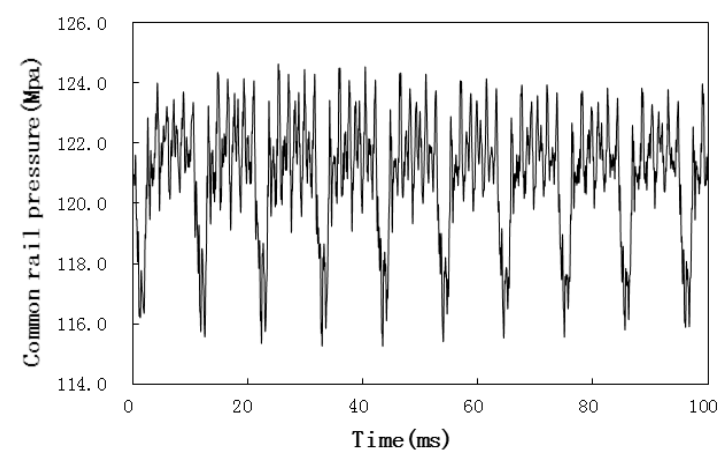

Figure 3. Curve of common rail pressure

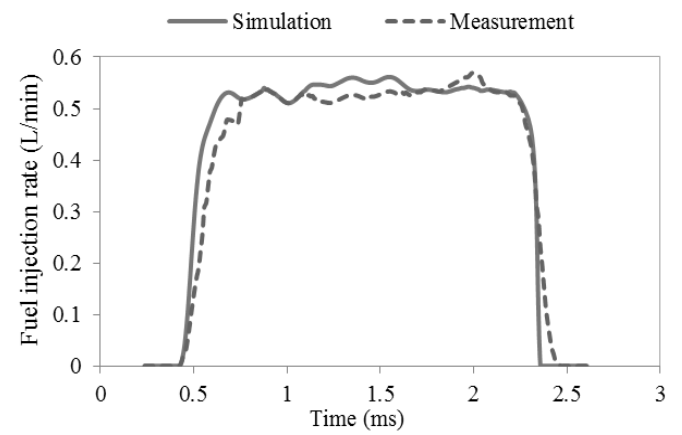

Figure 4. Comparison curve of fuel injection rate

\section{Influence of pilot injection to main injection fuel quantity}

Pilot and main injection fuel quantity were calibrated respectively as $6.2 \mathrm{~mm}^{3}$ and $60.0 \mathrm{~mm}^{3}$. MIFQ fluctuation with DT from $2{ }^{\circ} \mathrm{CA}$ to $32{ }^{\circ} \mathrm{CA}$ in the process of pilot-main injection simulation experiments is shown in Fig.5. It shows that influences of the same pilot injection are different from the main injection with different dwell times. MIFQ varies with DT like cosine curve, and the minimum fuel quantity is $58.3 \mathrm{~mm}^{3}$ while the maximum is $61.9 \mathrm{~mm}^{3}$. The fluctuation amplitude is $3.6 \mathrm{~mm}^{3}$.

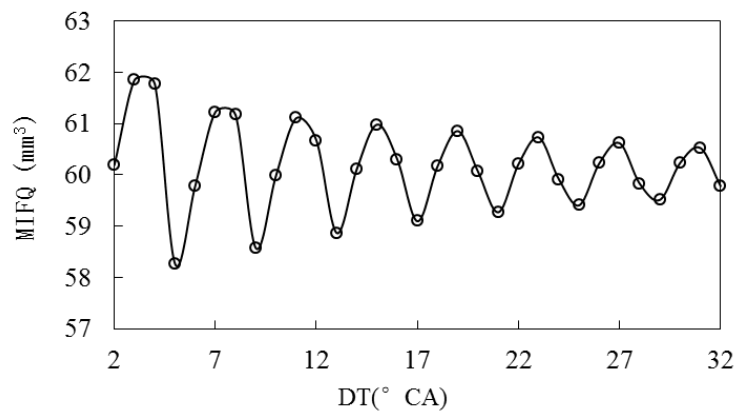

Figure 5. Fluctuation of MIFQ with DT

Simulation experiments of pilot-main injection with different dwell times conducted in this paper. Delivery chamber pressure and needle valve lift (NVL) curves are showed in Fig. 6 when dwell times are $4{ }^{\circ} \mathrm{CA}, 18{ }^{\circ} \mathrm{CA}$ and $32{ }^{\circ} \mathrm{CA}$. It shows that pilot injection causes drastic pressure fluctuation in delivery chamber. Though the pressure fluctuations with the same pilot injection are identical, main injection fuel quantities are different because of needle valve's diverse opening and falling moments with different dwell times. So it is the coupling of needle valve response and pressure fluctuation caused by needle valve action that impacts the MIFQ.
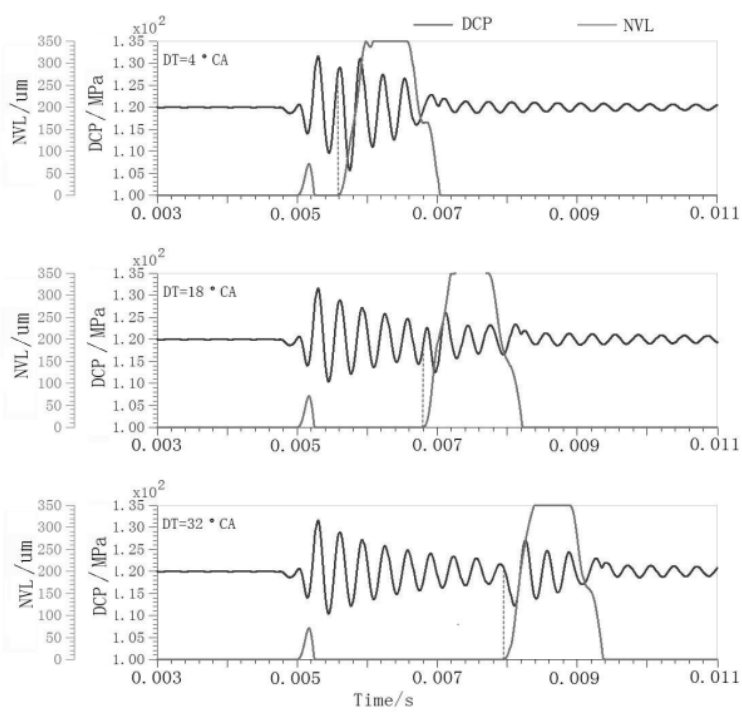

Figure 6. Delivery chamber pressure and needle valve response curve with different DTs

\section{Analysis to the coupling of needle valve response and pressure fluctuation}

Fuel injection quantity can be calculated by liquid flow formula (1) [5]:

$$
Q=\int_{0}^{t} C_{A} A \sqrt{\frac{2}{\rho}(P 1-P 2)}
$$


Where: $\mathrm{Q}=$ liquid flow $\left(\mathrm{m}^{3}\right) ; \mathrm{t}=$ flowing time $(\mathrm{s}) ; \mathrm{A}=$ Cross-sectional area $\left(\mathrm{m}^{2}\right) ; \rho=$ fluid density $\left(\mathrm{kg} / \mathrm{m}^{3}\right) ; \mathrm{CA}=$ flow coefficient; $\mathrm{P} 1=$ inlet pressure(pa), $\mathrm{P} 2=$ outlet pressure(pa).

By the nature of the integral calculation, when the $\rho$ and CA are fixed, cycle injection fuel quantity is determined by the product of pressure difference between $\mathrm{P} 1$ and $\mathrm{P} 2$ with $\mathrm{A}$ in flowing time. In fuel injection system, $\mathrm{P} 1$ is delivery chamber pressure, $\mathrm{P} 2$ is cylinder pressure. Because $\mathrm{P} 2<<\mathrm{P} 1$, so $\mathrm{P} 1-\mathrm{P} 2 \approx \mathrm{P} 1$, cycle fuel injection quantity is related to the integral value of $\mathrm{P} 1$ in injection pulse width [6].

\subsection{Opening stage of needle valve}

Delivery chamber pressure and needle valve response are shown in figure 7 when dwell times are $9{ }^{\circ} \mathrm{CA}$ and $11{ }^{\circ} \mathrm{CA}$. According to the simulation experiment, if the crankshaft speed set as $2000 \mathrm{r} / \mathrm{min}$, so the difference of needle valve action time should be about $0.167 \mathrm{~ms}$ when DT differs $2{ }^{\circ} \mathrm{CA}$. But the needle valve opening stage of two curves in Figure 7 has only $0.115 \mathrm{~ms}$ time difference, in terms of this tiny time difference, it results from when $\mathrm{DT}=9^{\circ} \mathrm{CA}$, needle valve opening time is at the wave trough of delivery chamber pressure, so the absolute value of pressure is lower(about $113 \mathrm{MPa}$ ). To lift the needle valve, the control chamber needs longer oil drainage time to reach lower pressure to make the fuel in delivery chamber can get over the control of chamber fuel pressure and the initial tension of spring. The needle valve opening time is delayed, circulation time is shortened.

Meanwhile, when $\mathrm{DT}=9^{\circ} \mathrm{CA}$, the main injection needle valve elevates at the wave trough of delivery chamber pressure, then the rising speed of delivery chamber pressure is obviously decreased, with a long time past, it will approach the new wave crest as shown in the area of the oval dotted line.

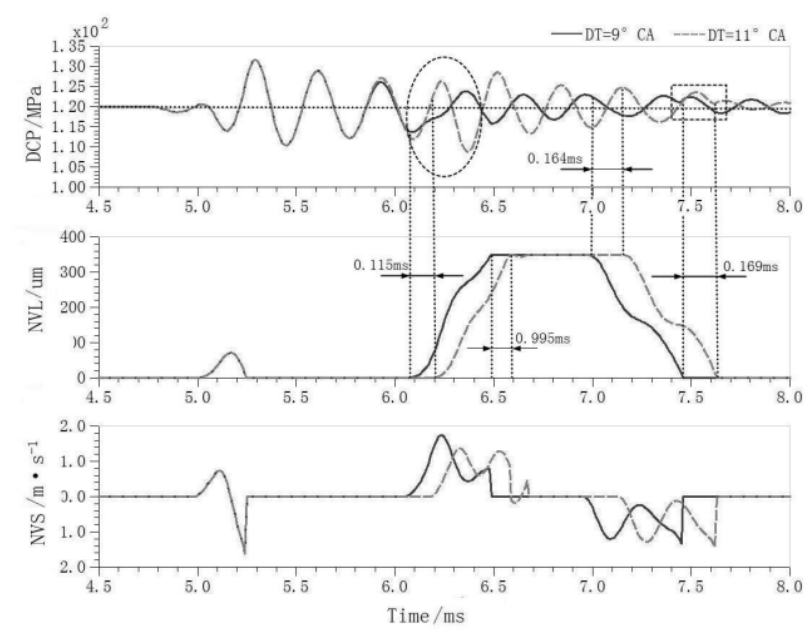

Figure 7. Delivery chamber pressure and needle valve response when DTs are $9{ }^{\circ} \mathrm{CA}$ and $11{ }^{\circ} \mathrm{CA}$

\subsection{Falling stage of the needle valve}

As shown in Figure 7, when $\mathrm{DT}=9^{\circ} \mathrm{CA}$, needle valve dropping time is under the wave crest of delivery chamber pressure(about $123 \mathrm{MPa}$ ), while $\mathrm{DT}=11^{\circ} \mathrm{CA}$, needle valve dropping time is at the wave crest of delivery chamber pressure(about $125 \mathrm{MPa})$. The difference of dropping time between two curves is $0.164 \mathrm{~ms}$, it differs with the equivalent time of $2{ }^{\circ} \mathrm{CA}$ phase only $0.003 \mathrm{~ms}$. Here is the reasons: in the process of fuel inlet in control chamber, the oil inlet opens only, and the oil outlet is closed, the pressure building process is faster than the pressure leak process when the needle valve is lifting. Thus, it is able to form high pressure at control chamber in a short time which makes the influence of delivery chamber pressure difference shorter.

To sum up, the pressure fluctuation which caused by pilot injection can influence the cycle fuel injection quantity mainly through influencing the needle vale opening stage of main injection. Therefore, main injection fuel quantity depends on its location of delivery chamber pressure fluctuation, in other words, it depends on DT.

\section{Decoupling analysis of the coupling between needle valve response and pressure fluctuation}

Because the capacity of the hydraulic container is similar to the capacitor, the hydraulic pipeline has the same electrical inductance on the delay, choked flow and oscillation. Therefore, when one-dimensional unsteady flow dynamic of high pressure oil pipe is analyzed regardless of damping and throttling effect, the system can be regarded as a circuit system of capacitance and inductance [7-8].

Figure 8 shows the model of the LC common rail system without damping hydraulic system, where $\mathrm{P}_{1}$ and $\mathrm{C} 1$ are common rail pressure and liquid capacity respectively, $\mathrm{P}_{2}$ is injector inlet pressure, $\mathrm{C}_{2}$ is the liquid capacity of high pressure fuel pipe and injector inlet chamber, $\mathrm{P}_{3}$ is delivery chamber pressure, $\mathrm{C}_{3}$ is the liquid capacity of the injector's internal oil duct and delivery chamber, $L_{12}$ and $F_{12}$ are fluid inductance and mass flow rate of high pressure oil pipe respectively, $\mathrm{L}_{23}$ and $\mathrm{F}_{23}$ are fluid inductance and mass flow rate of internal oil duct respectively.

From the analysis of Section 3, if the delivery chamber pressure fluctuation $\mathrm{P}_{3}$ can be mitigated, the amplitude of the main fuel injection quantity can be reduced accordingly to decouple the coupling between needle valve response and pressure fluctuation. As shown in Figure $8, \mathrm{~L}_{23}$ and $\mathrm{C}_{3}$ are directly related to $\mathrm{P}_{3}$, by changing the structure of the injector itself, values of $\mathrm{C} 3$ and $\mathrm{L}_{23}$ can be changed, therefore the fluctuation of delivery chamber pressure $\left(\mathrm{P}_{3}\right)$ can be influenced. According to the formula (2) and (3), the aspect ratio of internal oil duct and the volume of delivery chamber can influence the physical parameters of $\mathrm{L}_{23}$ and $\mathrm{C}_{3}$.

$$
\begin{aligned}
& L=l / A \\
& C=V / a^{2}
\end{aligned}
$$

where $l$ and $A$ respectively stands for the length (m) and cross-sectional area of the injector's internal oil duct $\left(\mathrm{m}^{2}\right)$, 
$V$ is the volume of the injector's internal oil duct $\left(\mathrm{m}^{3}\right)$ and the delivery chamber, a is the local velocity of sound $(\mathrm{m} / \mathrm{s})$.

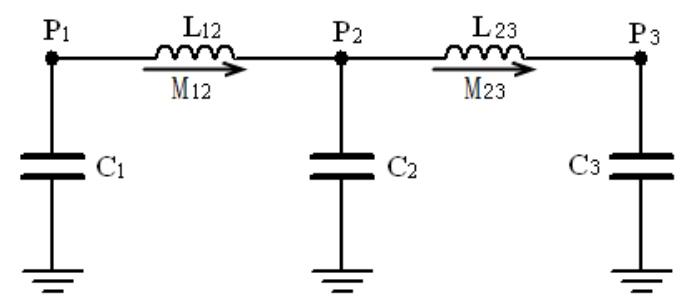

Figure 8. Non-damping LC hydraulic system model of HPCR

\subsection{Aspect ratio of injector's internal oil duct}

As shown in Figure 9, when injector's internal oil duct length contracts while the diameter expands, the amplitude of main injection fuel quantity with DT decreases obviously, and the speed of decay accelerates. When the length of oil duct extends from $2 \mathrm{~cm}$ to $10 \mathrm{~cm}$, the diameter varies from $3 \mathrm{~mm}$ to $2 \mathrm{~mm}$, the fluctuation amplitude of the main injection fuel quantity will decrease from $3.6 \mathrm{~mm}^{3}$ to $1.8 \mathrm{~mm}^{3}$, the descend range is as much as $50 \%$.

Therefore, it can reduce the degree of coupling between needle valve response and pressure fluctuation by decreasing the aspect ratio of internal oil duct. This method can be realized by removing the control piston which is above the injector needle valve, making the control chamber pressure directly acting on the upside of the needle valve, reducing the distance between the injector inlet and delivery chamber.

\subsection{Volume of the delivery chamber}

On the basis of reducing the aspect ratio of internal oil duct in the 5.1section, the volume of delivery chamber decreases to $0.02 \mathrm{~cm}^{3}$. As shown in Figure 10, the amplitude of main injection fuel quantity with DT has reduced to $1.7 \mathrm{~mm}^{3}$, the coupling degree between needle valve response and pressure fluctuation is further reduced. Therefore, by reducing delivery chamber volume can decouple the coupling between the needle valve response and pressure fluctuation as well, but the effectiveness is relatively limited.

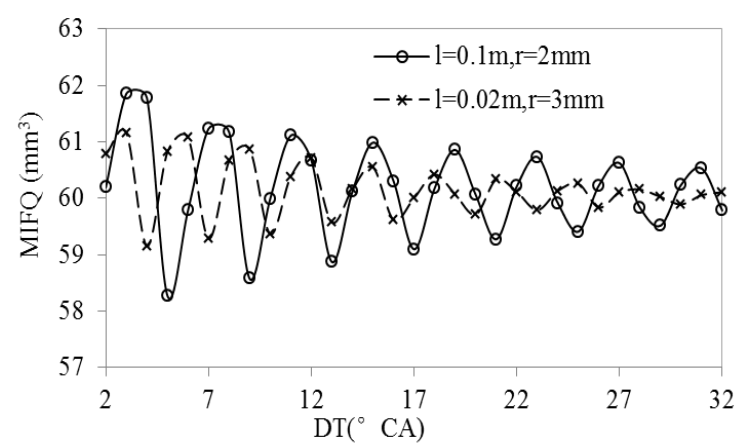

Figure 9. The influence of aspect ratio of internal oil to the main fuel injection quantity

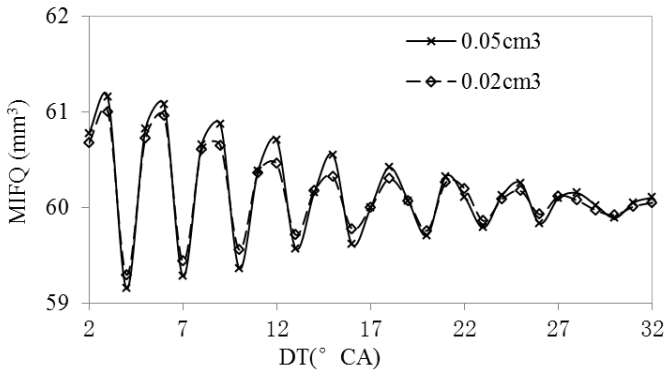

Figure 10. The influence of delivery chamber volume duct to the main fuel injection quantity

\section{Summary}

1. The main fuel injection quantity fluctuates with DT which is similar to the cosine curve at pilot-main injection, when the main injection base quantity is $60.0 \mathrm{~mm}^{3}$, the fluctuation amplitude is $3.6 \mathrm{~mm}^{3}$.

2. The pressure fluctuation in delivery chamber which caused by pilot injection is the fundamental reason of influencing the main fuel injection quantity. The pressure fluctuation can couple with needle valve response, and then change the action rules of the needle valve at opening stage, thereby it affects the main injection fuel quantity.

3. By reducing the aspect ratio of internal oil duct and delivery chamber volume can decouple the coupling between needle valve response and pressure fluctuation, and the effect of reducing aspect ratio of internal oil duct is very remarkable.

\section{References}

1. Ma Xiuzhen, Tian Bingqi, Fan Liyun, etal. Quantitative Analysis on the Effects of Parameters of Electronic Injector on the Cycle Fuel Injection Quantity Fluctuation of High Pressure Common Rail System[J]. Automotive Engineering 2015 , Vol.37(1):55-61.

2. Saud Aldajah, Mohamed Y E Selim. Tribological Behavior of Dual Fuel Diesel Engine[J]. International Journal of Mechanical Engineering and Robotics Research, Vol. 2, No. 2:41-50, April 2013

3. Liu Zhen-ming, Shao Li-ming, OuYang Guang-Yao, etal. Optimization Study On Injection System Parameters Of Common Rail Diesel Engine Based On Approximate Model $[\mathrm{J}]$.Chinese Internal Combustion Engine Engineering, 2011 , 32(6):63-67,73.

4. Mikio Kumano, Kenzo Yano, Kanehito Nakamura, etal. Advanced Electronics for a Clean Diesel Engine Management System[C]. SAE Paper 2006-21-0059, 2006.

5. Zheng Jinbao, Liao Xuelong, Hong Jianmei, etal. Measurement and Analysis of Pressure of Nozzle Volume in Electric Solenoid Common-Rail System $[\mathrm{J}]$. Transactions of CSICE, 2012, Vol.30(1):86-90.

6. Andrea E. Catania, Alessandro Ferrari, etal. Experimental Investigation of Dynamics Effects on 
Multiple-Injection Common Rail System Performance $[\mathrm{J}]$. Engineering for Gas Turbines and Power, MAY 2008, Vol. 130 / 032806.

7. $\mathrm{Su}$ Haifeng, Zhang Youtong, Luo $\mathrm{Xu}$, etal. Experimental Investigation on Water Hammer Pressure Wave in High Pressure Common Rail System[J]. Transactions of CSICE, 2011, 29(2), 163-168.
8. Andrea E. Catania, Alessandro Ferrari, Ezio Spessa. Numerical-Experimental Study and Solutions to Reduce the Dwell-Time Threshold for Fusion-Free Consecutive Injections in a Multijet Solenoid-Type CR System[J]. Engineering for Gas Turbines and Power, MARCH 2009, Vol. 131 / 022804. 